\title{
Inconsistencies in the Relationship Between Contraceptive Use and Fertility in Bangladesh
}

\begin{abstract}
CONTEXT: Contraceptive prevalence increased by nine percentage points from 1993 to 2000 in Bangladesh, but there was almost no decline in the total fertility rate.
\end{abstract}

METHODS: Data from the 1999-2000 Bangladesh Demographic and Health Survey and from the Matlab Demographic Surveillance System area collected between 1978 and 2001 were analyzed to explain the lack of change in fertility and to examine relationships among contraceptive prevalence, the abortion ratio, desired fertility and total fertility.

RESULTS: After a maternal and child health and family planning program was initiated in part of Matlab in 1977, the total fertility rate in the intervention area declined from 4.8 in 1979 to 2.9 in 2000, while fertility in the comparison area dropped from 6.3 to 3.5 . Over this period, contraceptive prevalence rose from $30 \%$ to $70 \%$ and from $16 \%$ to $50 \%$ in the two areas, respectively; meanwhile, the abortion ratio fell from 4.3 to 3.6 in the intervention area, but rose from around two to 8.2 in the comparison area. Trends in desired fertility in each area were similar, declining from about 4.0 children per woman in 1979 to about 2.5 children in 2000. Among women at each level of parity, fertility generally decreased as the number of sons increased, and fertility was highest for women without sons.

CONCLUSIONS: Preference for male children and parental concern over infant and child mortality may partially explain the difference between desired family size and fertility. A reduction in breast-feeding and an increase in use of less-effective contraceptive methods might be responsible for the inconsistency in the relationship between contraceptive use and fertility.
By Unnati Rani

Saha and

Radheshyam

Bairagi

Unnati Rani Saha is research officer, International Centre for Diarrhoeal Disease Research, Dhaka, Bangladesh, and Radheshyam Bairagi is adjunct professor, Department of Sociology and Anthropology, Fordham University, New York
During the mid-1970s, the contraceptive prevalence rate (CPR) in Bangladesh was less than 10\% and the total fertility rate (TFR) was more than six births per woman. ${ }^{1}$ By 1993-1994, according to the first Bangladesh Demographic and Health Survey (DHS), the CPR had risen to $45 \%$ and the TFR had fallen to 3.4. ${ }^{2}$ The subsequent two rounds of the DHS, in 1996-1997 and 1999-2000, found CPRs of $49 \%$ and $54 \%$, respectively, yet the TFRs for those years were 3.4 and 3.3.3,4 According to the widely accepted correlation between CPR and TFR, a rise of nine percentage points in CPR should be accompanied by a fall of 0.64 in the TFR. ${ }^{5}$ The lack of such an effect in Bangladesh raises questions about the country's fertility dynamics and prospects for future fertility decline.

How can fertility remain stable while contraceptive use is increasing? A genuine decline in fertility during this period could have been concealed by an underestimate of fertility in the 1993-1994 DHS. However, data from the Matlab Demographic Surveillance System (DSS) and DHS data yielded similar estimates for the TFR of the DSS area. ${ }^{6}$ Moreover, fertility in two of the most important DSS areas in the country-Matlab and Abhoynagar-has been stable since the early 1990s, ${ }^{7,8}$ despite substantial increases in the CPR in both areas. The Matlab and Abhoynagar results suggest that there has, in fact, been a pause in fertility decline in Bangladesh.
Some researchers strongly believe that family planning programs played the main role in the rapid fertility decline that occurred in less developed countries in the 1980s and 1990s. For example, Cleland et al. conclude that the Bangladesh family planning program was the main factor in fertility decline during the mid-1970s and 1980s. ${ }^{9}$ Others argue that a family planning program alone cannot have major effects on fertility. For instance, Caldwell et al. express doubt that the Bangladesh family planning program could have reduced the TFR by approximately three births per woman over two decades in the absence of significant social change. ${ }^{10}$

The same controversy exists regarding the fertility decline in the developing world in general. Robey et al. argue that family planning has the most direct influence on fertility. ${ }^{11}$ Becker, however, asserts that the major change in fertility has not resulted from increased use of birth control, but rather from changes in the demand for children. ${ }^{12}$ In a similar vein, Pritchett states that desired fertility is an important influence on reducing fertility in a population, and that a family planning program and even contraceptive use play very minor roles in decreasing fertility. ${ }^{13}$ Bairagi and Datta's work supports his argument, ${ }^{14}$ as do Bangladesh DHS data on the historical trends of TFR and CPR. In this study, we will use Matlab data and DHS data for 1999-2000 to explore the relationship between these two measures. 


\section{MATLAB}

Data

The Matlab DSS of the International Centre for Diarrhoeal Disease Research, Bangladesh encompasses a population of about 200,000. In the DSS, community health workers have collected data on births, deaths and migration in semimonthly home visits since 1966, and in monthly visits since 1997. * Their work is supervised and checked at different levels, so the Matlab data are considered to be of high quality.

To test the hypothesis that a demographic change can be induced in a poor society through an intensive public health program without any intervention directed at socioeconomic conditions, the International Centre initiated a maternal and child health and family planning program in October 1977 in half of the DSS area. The other half, known as the comparison area, remained under the government-run health program, which offered limited primary health care and some family planning services. Before the project began in 1977, the two areas were demographically and socioeconomically similar. ${ }^{15-17}$

All of the women in each area were included in the study. If a woman reported she was pregnant or was observed to be pregnant during a routine visit, this was recorded by a community health worker. Oral contraceptives, condoms and injectables were delivered to women's homes in the intervention area; only oral contraceptives and condoms were delivered in the comparison area, and injectable users were required to visit Family Welfare Centres. Both areas had these government-managed clinics; however, regular supplies of contraceptives were ensured only in the intervention area. The program had a system for routine recording and monitoring of services; no such system existed in the comparison area. In addition, contraceptive side effects were more comprehensively managed in the intervention area.

Some induced abortions in Matlab were reported as spontaneous abortions, ${ }^{18}$ and the number of abortions was found to be underestimated. ${ }^{19}$ Yet the prevalence of misclassification and underestimation is thought to be constant over time and between areas, because the same procedures were followed in the two areas throughout the period of study. In this study, an abortion was defined as an induced abortion (including menstrual regulation), and the abortion ratio was the ratio of abortions to live births multiplied by 100. The program discontinued provision of menstrual regulation services in 1984. Since then, women in the intervention area who want menstrual regulation are advised to visit a government clinic.

The desired family size was available for 1975, 1984 and 1999 from three sample surveys conducted in Matlab (because data were linked to specific villages, this measure could be determined separately for the two areas). From

*From 1966 to September 1977, the outcome of a pregnancy was recorded as a live birth, a stillbirth or "fetal wastage" (i.e., spontaneous or induced abortion); beginning in October 1977, the outcomes of spontaneous abortion and induced abortion were specifically identified. Marital status has been recorded since 1974, and data have been collected separately for intervention and comparison areas since 1978. these data, the desired levels of fertility for 1979-2000 were estimated by interpolation and extrapolation. Three-year moving averages (which combine the year of record with those immediately preceding and following that year) of the CPR, TFR and abortion ratio were determined for the years 1979-2000 for the intervention and comparison areas, and trends in both areas were compared to investigate the relationships among the four measures.

\section{Results}

Contraceptive prevalence in the two areas diverged within a few years of the initiation of the maternal and child health and family planning program. In 1979, the threeyear moving averages for the CPR in the intervention and comparison areas were $30 \%$ and $16 \%$, respectively, but in the former area it rose to $46 \%$ by 1984 and to $59 \%$ by 1989 (Figures 1 and 2). In 1996, the CPR was 20 percentage points higher in the intervention area than in the comparison area (68\% vs. 48\%).

Following program initiation, the intervention area showed greater declines in both fertility and infant mortality than did the comparison area. The TFR, which in 1979 was 4.8 in the intervention area and 6.3 in the comparison area, remained one child lower in the intervention area from 1979 to 1996, while under-five mortality remained about 20 percentage points lower (not shown). However, by the late 1990s, the TFRs-2.9 in the intervention area and 3.5 in the comparison area-differed little.

The abortion ratio was estimated to be about two in both areas in 1977. (Abortion data were not collected separately by area before 1978; however, since the two areas were demographically similar prior to this time, ${ }^{17}$ it can reasonably be assumed that the abortion ratios were also similar.) The ratio increased to 4.3 in the intervention area by 1979. This rise was mainly attributed to the newly available menstrual regulation services of the program.

As the figures show, desired fertility declined from about 4.0 children per woman in 1979 to about 2.5 in 2000 . The TFRs in both areas also declined, but the difference between the two indicators was much greater in the comparison area than in the intervention area until the mid-1990s. Because the abortion ratio did not increase greatly in the intervention area, this difference is likely due mainly to the higher CPR in this area. During the 1990s, however, the two indicators converged more noticeably in the comparison area, as the CPR rose dramatically-from 16\% in 1989 to $50 \%$ in 2000. Between 1990 and 2000, the CPR in the intervention area increased from $61 \%$ to $70 \%$. Changes in the abortion ratio also differed markedly between the two areas during this period: In the intervention area, the ratio fluctuated between 2.1 and 3.7 per 100 live births, whereas in the comparison area, it rose steadily from 4.4 to 8.2 per 100 .

What was the role of contraception in reducing the level of abortion in Matlab? Bongaarts and Westoff ${ }^{20}$ demonstrate that the total abortion rate decreases as the CPR and the desired level of fertility increase. The abortion ratio in the intervention area declined from 1979 to 1983, mainly 
FIGURE 1. Contraceptive prevalence, abortion ratio, desired fertility and total fertility rate in the Matlab intervention area, 1979-2000

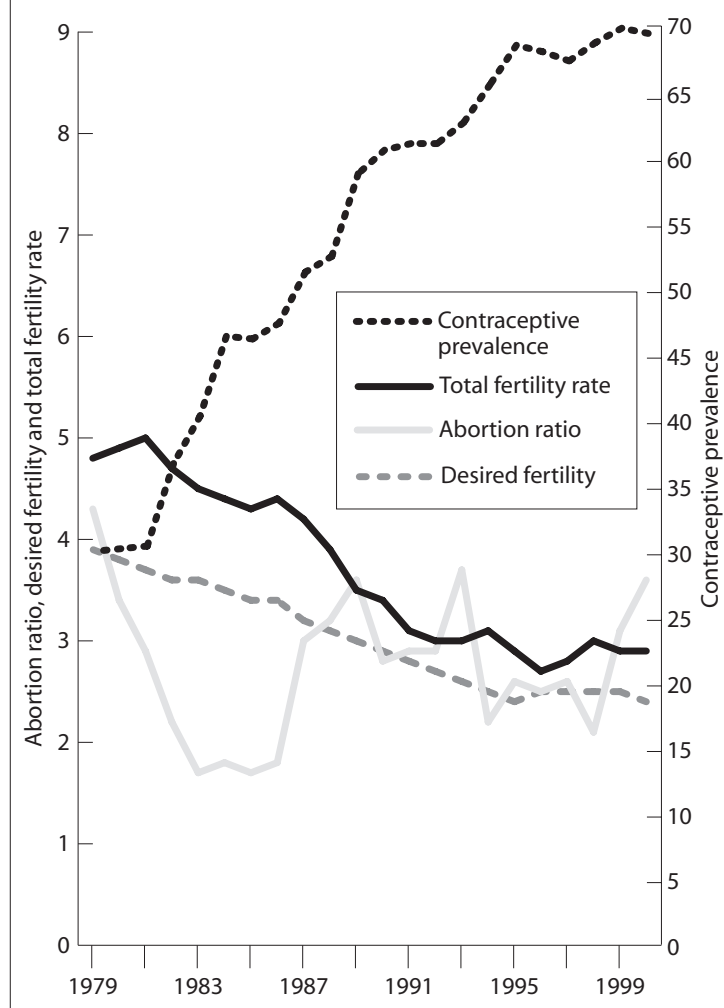

Note: Contraceptive prevalence, abortion ratio and total fertility rate are plotted as three-year moving averages.

because of an increase in the CPR (see Figure 1). With the CPR continuing to rise from 1986 to 1990, we would expect a further decrease in the abortion ratio, yet the results show the opposite. The increase in the abortion ratio during this period may have been the result of an increase in the probability of abortion of an unintended pregnancy and a decrease in desired fertility (the latter attributed to a weakening of social taboos regarding abortion and a rise in socioeconomic status during this period), ${ }^{9,16}$ which together outweighed the effect of the rising CPR. From 1990 on, the negative effect on the abortion ratio of increases in the CPR was balanced by the positive effect of increases in the probability that an unintended pregnancy would end in abortion and decreases in desired fertility.

In the comparison area, the abortion ratio increased from 1979 to 2000, as did the CPR (see Figure 2). The negative effect of the increasing CPR on the abortion ratio was outweighed by the positive effect of an increased probability of abortion and a decline in desired fertility. Except at the beginning of the intervention program, when menstrual regulation services were available, the abortion ratio was always higher in the comparison area.

These results suggest that the total fertility rate of a population will eventually approach its desired level of fertility. Proximate determinants of fertility, such as contraception and abortion, contribute to this convergence. An intervention program may help lower total fertility to the level of desired fertility; in the case of Matlab, a dramatic rise in CPR narrowed the difference quite rapidly. However, when a woman's contraceptive use fails to keep her fertility within the desired level, she may turn to abortion or voluntary sterilization. In the Bongaarts and Westoff equation, ${ }^{20}$ the relationship between contraception and abortionship is negative; that is, increases in contraceptive use are associated with decreases in abortion. However, this relationship is rather complex and depends on the values of other variables in the equation. For example, the relationship may be positive (as found in the comparison area during the period 1979-2000), negative (as found in the intervention area in 1979-1986), or neutral (as found in the intervention area in 1991-2000), depending on the probability that an unintended pregnancy will end in abortion, the desired level of fertility, the effectiveness of contraceptive use, and the relative material, social and cultural costs of contraceptive use and abortion. If a program's goal is to lower the abortion rate by increasing contraceptive use, the target CPR should be sufficiently high to prevent most unintended pregnancies. This situation existed in the Matlab intervention area from 1979 to 1986.

In Matlab, the desired fertility in 2000 was 2.5, but the TFR stabilized at 2.9 in the intervention area and at 3.5 in the comparison area. This raises two questions: At this stage of TFR stabilization, why is there a difference of 0.6 in the TFR between the two areas, and why is there any difference between the desired family size and the TFR? The differ-

\section{FIGURE 2. Contraceptive prevalence, abortion ratio, desired fertility and total fertility rate in the Matlab comparison area, 1979-2000}

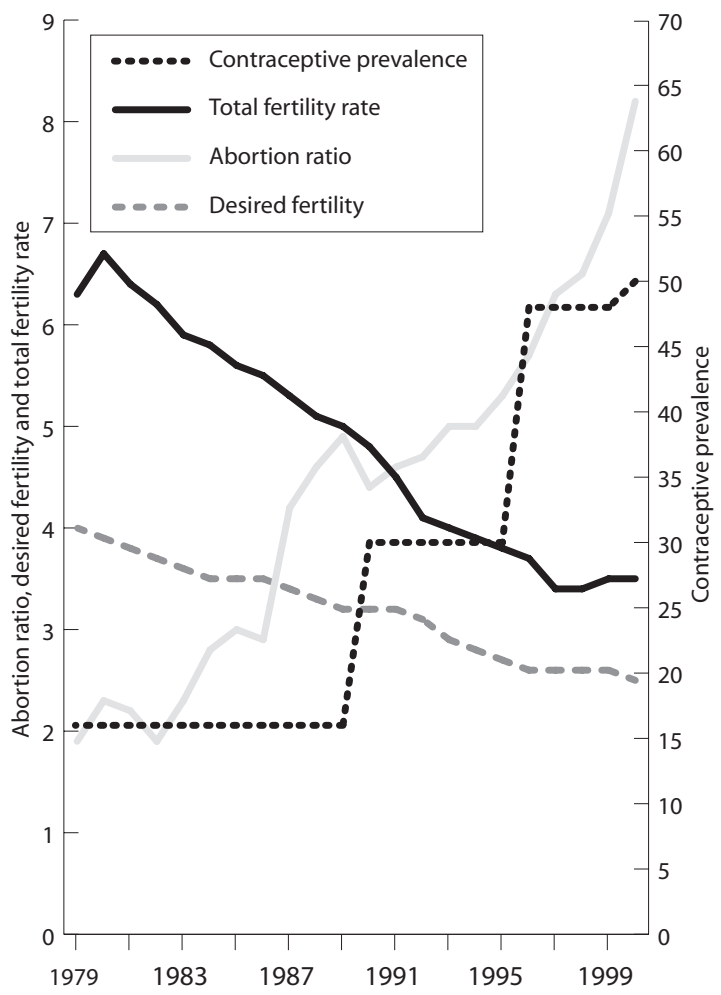

Note: Contraceptive prevalence, abortion ratio and total fertility rate are plotted as three-year moving averages. 


\begin{tabular}{|c|c|c|c|}
\hline $\begin{array}{l}\text { Parity and } \\
\text { no. of sons }\end{array}$ & $\begin{array}{l}\text { No. of } \\
\text { women }\end{array}$ & $\begin{array}{l}\text { \% giving } \\
\text { birth }\end{array}$ & $\begin{array}{l}\text { Mean no. } \\
\text { of births }\end{array}$ \\
\hline All & 8,462 & 37 & na \\
\hline Parity 0 & 1,148 & 72 & 0.86 \\
\hline Parity 1 & 1,767 & 54 & 0.58 \\
\hline 0 & 836 & 56 & 0.60 \\
\hline 1 & 931 & 52 & 0.56 \\
\hline Parity 2 & 1,846 & 44 & 0.36 \\
\hline 0 & 376 & 46 & 0.47 \\
\hline 1 & 943 & 30 & 0.32 \\
\hline 2 & 527 & 33 & 0.37 \\
\hline Parity 3 & 1,440 & 24 & 0.26 \\
\hline 0 & 147 & 37 & 0.42 \\
\hline 1 & 534 & 23 & 0.25 \\
\hline 2 & 602 & 21 & 0.22 \\
\hline 3 & 157 & 29 & 0.29 \\
\hline Parity 4 & 983 & 21 & 0.23 \\
\hline 0 & 47 & 40 & 0.47 \\
\hline 1 & 246 & 20 & 0.23 \\
\hline 2 & 370 & 22 & 0.23 \\
\hline 3 & 258 & 17 & 0.18 \\
\hline 4 & 62 & 21 & 0.26 \\
\hline Parity $\geq 5$ & 1,278 & 15 & 0.17 \\
\hline 0 & 24 & 17 & 0.21 \\
\hline 1 & 162 & 21 & 0.23 \\
\hline 2 & 328 & 14 & 0.16 \\
\hline 3 & 370 & 14 & 0.16 \\
\hline 4 & 246 & 14 & 0.16 \\
\hline$\geq 5$ & 148 & 20 & 0.23 \\
\hline
\end{tabular}

ence between areas is most likely due to the difference in the quality of family planning services available in the areas. The difference between the desired level of fertility and the TFR is likely attributable to a preference for male children, * a desire for security against infant and child mortality, a lack of optimum family planning facilities and contraceptive failure. $^{21,22}$

Although the Matlab data dispel much of the confusion regarding the stabilization of fertility despite increasing contraceptive prevalence, further investigation is needed to confirm the validity of this conclusion, particularly at the national level. In the next section, we will examine the influence of sex preference and infant and child mortality on fertility, as well as why an increase of nine percentage points in the CPR had no effect on the TFR at the national level.

*It has been demonstrated that actual fertility will be much higher than desired fertility when there is a preference for male children (source: Sheps MC, Effects on family size and sex ratio of preferences regarding the sex of children, Population Studies, 1963, 17(1):66-72). Van Mels argued that, with a desired fertility of 2.5 children, actual fertility may be as high as 3.4 because of the preference for male children (source: Van Mels CT, Influence of sex preference on family size and composition, unpublished manuscript, Dhaka, Bangladesh: Centre for Health and Population Research, ICDDR,B, 2001).

\section{DEMOGRAPHIC AND HEALTH SURVEY \\ Data}

National-level data were from the $1999-2000$ DHS, ${ }^{4}$ which collected information on fertility, history of contraceptive use and desired family size from 10,544 ever-married women aged 10-49, of whom 9,696 were currently married and aged 15-49. The main dependent variable-the fertility of currently married women-was measured by both the percentage of women giving birth and the average number of children born in the three years prior to the survey, which were cross-tabulated by parity and number of sons. Desired family size was used as a dependent and also as an independent variable. The main independent variables were parity and sex composition of children by parity; other variables were socioeconomic status, education, urban or rural residence, and demographic characteristics such as age and sex. Both univariate and multivariate techniques (odds ratios and coefficients) were used for data analysis.

The effect of sex preference on fertility was measured by an index suggested by Arnold, ${ }^{23}$ and modified by Chowdhury and Bairagi. ${ }^{24}$ This index is defined as the ratio of the absolute difference between observed and expected fertility measures (contraceptive use, mean ideal number of children, fertility) to the observed value multiplied by 100. In estimating the expected rate for the various measures, we assumed that all couples with a given parity will act in the same manner as those who are currently most satisfied with their number of sons and daughters. The index is not affected by reporting errors on events (e.g., contraceptive use, abortion) unless the proportion of error differs by sex composition of children by parity. Couples were assumed to be most satisfied at the parity at which contraceptive use was highest and at which fertility and desire for more children were lowest.

\section{Results}

Among currently married women aged $15-49$, fertility data were analyzed for 8,462 individuals (Table 1). Fertility declined with rising parity: Seventy-two percent of women with no children gave birth in the three-year period, as did $54 \%$ of those with one child, $44 \%$ of those with two children and $24 \%$ of those with three children (the mean number of births in this period declined from 0.86 for women with no children to 0.26 for women with three children). Within each parity level, fertility also generally decreased as the number of sons increased. Within parity levels of one to four, fertility was highest for women without sons; for example, among women who had two children, $46 \%$ of those without a son gave birth, whereas 30\% of those with a son did so. These data suggest that, although a preference for sons was present, couples also wanted a daughter. Among women with two or more children, those who had at least one son and a daughter had the lowest fertility. The relationship of fertility with parity and sex composition of children did not vary according to the mother's background characteristics (not shown).

While the basic relationship between the sex composi- 
tion of children and fertility is clear, it is important from a program and policy viewpoint to determine the magnitude of the effect of sex preference on fertility. Observed fertility, as measured by both the overall percentage of women giving birth and the average number of births per woman in the three years before the survey, was higher than expected fertility, suggesting that fertility would decrease by about $6 \%$ in the absence of a preference for male children. ${ }^{24}$ Given the country's 1999-2000 TFR of 3.3, a 6\% decrease would reduce the TFR by about $0.2(3.3 \times 0.06)$ per woman.

One school of thought argues that to reduce fertility in a population, desired family size should be brought down first by promoting small family size through economic development and other means. In fact, fertility in Bangladesh has stabilized, or at least its decrease has been substantially slowed, since the early 1990s. Meanwhile, desired family size among currently married women has declined from 4.1 in 1975 to 2.9 in 1989 and 2.5 in 1993-1994; it has remained at this level since then. ${ }^{4,25}$

It is interesting to note that the general trend in desired family size has been similar to that of the TFR in the country: The TFR was about 7.0 in the early 1970s, dropped to 3.4 in the 1993-1994 DHS, and has since remained more or less stable. The difference between the TFR and the desired family size was about three children in the 1970s, and declined to 0.8 in the late 1990 s (3.3 vs. 2.5).

A comparison of the mean ideal number of children by women's selected background characteristics revealed that this number declines with increasing education level, and is lower among urban women and those with some exposure to mass media (Table 2). Multivariate analysis found that desired family size was negatively associated with women's education (coefficient of -.036 for women with some education compared with those with no education), exposure to mass media at least once a week (-.062) and socioeconomic status (-.048 for women in the richest quintile compared with those in the poorest), ${ }^{26}$ but was positively associated with parity and age (not shown). Multivariate analysis also supported the bivariate findings on fertility, which was negatively associated with women's education (odds ratio of 0.77 for women with some vs. no education) and socioeconomic status (with odds ratios de-

\begin{tabular}{|c|c|}
\hline Characteristic & $\begin{array}{l}\text { Mean no. } \\
(\mathrm{N}=9,696)\end{array}$ \\
\hline All & 2.5 \\
\hline \multicolumn{2}{|l|}{ Education } \\
\hline None & 2.7 \\
\hline Primary & 2.5 \\
\hline Secondary & 2.3 \\
\hline \multicolumn{2}{|l|}{ Residence } \\
\hline Rural & 2.6 \\
\hline Urban & 2.3 \\
\hline \multicolumn{2}{|c|}{ Mass media exposure } \\
\hline None & 2.7 \\
\hline Some & 2.3 \\
\hline
\end{tabular}

clining from 0.82 for women in the second-poorest quintile to 0.64 for women in the richest quintile, compared with those in the poorest). However, unlike desired family size, fertility was negatively associated with parity and age.

This difference in the direction of association can be attributed to the fact that most women of high parity and age have already reached or exceeded their desired number of children, and hence they are more likely to control their fertility by using contraceptives or other methods than are young females of low parity. Furthermore, their fecundity is lower than that of young women, and women with high parity are also more likely to justify their actual number of children.

\section{DISCUSSION}

Policymakers and planners in Bangladesh are concerned about two major demographic issues: The total fertility rate has not declined since 1993-1994, and a substantial increase in the use of contraceptives over the period 19932000 has had no effect on fertility.

The Matlab data show that the total fertility rate has declined toward the desired family size. Furthermore, trends in TFR and desired family size in the two areas are similar. But how can one explain the difference of 0.8 between the national TFR and desired family size (3.3 vs. 2.5) in 2000 ? Can this be attributed to a preference for male children?

This study estimated that, in the absence of a preference for male children, there would be a reduction of about 0.2 in the national TFR. Yet this reduction would explain only a quarter of the observed difference. What other factors could be involved? One explanation is that this additional child provides security against the death of one of the family's children. In Bangladesh, life expectancy is about 60 years, at which age a woman's children would be approximately 30-40 years old. However, infant and child mortality in Bangladesh is very high, and about 30\% of women reported that one or more of their children had died in the three years prior to the survey. Notably, women who had experienced a child's death had 30\% more births in the following three years than did women who did not report such a death. We can estimate that 0.3 was added to the TFR because of infant and child mortality (30\% of $30 \%$ is $9 \%$, and $0.09 \times 3.3=0.3$ ). Hence, after taking these factors into account, expected family size would be 2.5 (desired fertility) +0.2 (sex preference) +0.3 (security against death of a child $)=3.0$. The remaining difference of 0.3 between the TFR and the desired family size could be the result of a lack of optimum levels of contraceptive use and contraceptive failure. ${ }^{27,28}$ Thus, while one of the strategies to reduce fertility should be bringing down the desired family size, other strategies to narrow the gap should include efforts to reduce the preference for male children and to lower infant and child mortality, as well as to promote the effective use of contraceptives.

The second demographic issue of concern is why the increase of nine percentage points in the CPR from 1993-1994 to 1999-2000 had no effect on the TFR. (An increase of nine percentage points in contraceptive prevalence should lower 
the TFR by $0.64 .^{5}$ ) One explanation is that the contraceptive method mix may have changed, with a decline in the use of more effective methods. Indeed, the use of traditional methods, such as the rhythm method, was higher in 1999-2000 than in 1993-1994 (10\% vs. 8\%). However, there was an increase in use of every modern method except the IUD (declining from $2 \%$ to $1 \%$ ) and sterilization (from $9 \%$ to $7 \%$ ). ${ }^{2,4}$ The cumulative decline of three percentage points for these two methods is expected to increase the TFR by 0.2 .

It seems unlikely that the change in method mix would negate the effect on fertility of a nine-point increase in CPR; thus, the effect of increased contraceptive use on fertility was probably counterbalanced by a reduction in the effect of one or more of the other proximate determinants on fertility. There has been no significant change in age at marriage or the proportion of married women in the country in recent years. The use of abortion, however, could be an important factor. ${ }^{29}$ The Bangladesh DHS data do not include estimates of the abortion rate, but about 750,000 abortions are estimated to occur annually; ${ }^{30}$ a rising abortion rate should reduce TFR, but this has not happened. Another important proximate determinant of fertility is postpartum amenorrhea. The median duration of breast-feeding has declined from 36 months in 1993-1994 to 31 months in 1999-2000.31 The median length of postpartum amenorrhea recorded was 10.3 months in the 1993-1994 DHS and 7.9 months in the 1999-2000 DHS. ${ }^{2,4}$ We estimated that this difference of 2.4 months compensates for an increase of four percentage points in contraceptive use in Bangladesh.* Further investigation of the interactions among desired fertility, TFR, CPR, the abortion ratio, postpartum amenorrhea and preference for male children is needed to improve our understanding of how these various elements influence each other.

Desired family size appears to have had a strong effect on fertility in Bangladesh. Yet desired fertility is in turn strongly affected by the level of development in a country. Furthermore, infant and child mortality declines as development increases. ${ }^{32,33}$ Most developing countries, including Bangladesh, want to reduce their fertility to replacement levels, and a recent study analyzing fertility transitions in 143 developing countries concluded that, on average, a life expectancy of 75 years and literacy near $95 \%$ are needed to approach this level. ${ }^{34}$ Because it may take a long time for some countries to achieve sufficient development, policymakers need to consider other approaches for reaching this goal, such as reducing son preference and infant and child mortality, as well as improving family planning programs and promoting breast-feeding.

*A woman who had three to four live births was protected from conception for about eight months longer (2.4 months x 3.4 births) in 1993-1994 than in 1999-2000 because of the longer period of breast-feeding and postpartum amenorrhea. Thus, she would need continuous protection for an other 18 years to avoid having more births (source: Islam MM and Islam MN, Birth spacing in Bangladesh: patterns, differentials and components, Bangladesh Journal of Scientific Research, 1995, 13(2):171-177). On a population level, this would translate to a four-percentage-point increase in the CPR ( 0.67 year $/ 18$ years)

\section{REFERENCES}

1. Islam MN and Islam MM, Biological and behavioural determinants of fertility in Bangladesh: 1975-1989, Asia-Pacific Population Journal, 1993, 8(1):3-18.

2. National Institute of Population Research and Training (NIPORT), Mitra and Associates, and Macro International, Bangladesh Demographic and Health Survey, 1993-1994, Dhaka, Bangladesh: NIPORT, 1994

3. NIPORT, Mitra and Associates, and Macro International, Bangladesh Demographic and Health Survey, 1996-1997, Dhaka, Bangladesh: NIPORT, 1997.

4. NIPORT, Mitra and Associates, and ORC Macro, Bangladesh Demographic and Health Survey, 1999-2000, Dhaka, Bangladesh: NIPORT, 2000.

5. Mauldin WP and Segal SJ, Prevalence of contraceptive use: trends and issues, Studies in Family Planning, 1988, 19(6):335-353.

6. Bairagi Ret al., An Evaluation of the 1993-94 Bangladesh Demographic and Health Survey Within the Matlab Area, Asia-Pacific Population Research Report, Honolulu, HI, USA: East-West Center, 1997, No. 11.

7. International Centre for Diarrhoeal Disease Research, Bangladesh (ICDDR,B), Health and Demographic Surveillance System-Matlab, Dhaka, Bangladesh: ICDDR,B, 2001, Vol. 34.

8. ICDDR,B, Health Systems and Infectious Diseases Surveillance System Report, 2000-2001, Dhaka, Bangladesh: ICDDR,B, 2004.

9. Cleland J et al., The Determinants of Reproductive Change in Bangladesh: Success in a Challenging Environment, Washington, DC: World Bank, 1998.

10. Caldwell JC et al., The Bangladesh fertility decline: an interpretation, Population and Development Review, 1999, 25(1):67-84.

11. Robey B, Rutstein SO and Morris L, The fertility decline in developing countries, Scientific American, 1993, 269(6):60-66.

12. Becker GS, A Treatise on the Family, enlarged ed., Cambridge, MA, USA: Harvard University Press, 1991.

13. Pritchett LH, Desired fertility and the impact of population policies, Population and Development Review, 1994, 20(1):1-55.

14. Bairagi R and Datta AK, Demographic transition in Bangladesh: what happened in the twentieth century and what will happen next? AsiaPacific Population Journal, 2001, 16(4):3-16.

15. Razzaque A et al., Demographic Surveillance System-Matlab: 1996 Socio-economic Census, Dhaka, Bangladesh: ICDDR,B, 1998, Vol. 29.

16. Razzaque A et al., Fertility intention and subsequent abortion in Matlab, Bangladesh, paper presented at the IUSSP XXIV general conference, Salvador, Bahia, Brazil, Aug. 18-24, 2001

17. LeGrand TK and Phillips JF, The effects of fertility reduction on infant and child mortality: evidence from Matlab in rural Bangladesh, Population Studies, 1996, 50(1):51-68.

18. Bhuiya A, Aziz A and Chowdhury M, Induced Abortion in Rural Bangladesh, Scientific Report, Dhaka, Bangladesh: ICDDR,B, 1999, No. 86.

19. Johnston HB, Induced abortion in the developing world: evaluating an indirect estimation technique, unpublished thesis, Baltimore, MD, USA: School of Hygiene and Public Health, Johns Hopkins University, 1999.

20. Bongaarts J and Westoff CF, The potential role of contraception in reducing abortion, Studies in Family Planning, 2000, 31(3):193-202.

21. Bongaarts J, Fertility and reproductive preferences in post-transitional societies, Population and Development Review, 2001, 27(Suppl.): 260-281.

22. Bairagi R, Effects of sex preference on contraceptive use, abortion and fertility in Matlab, Bangladesh, International Family Planning Perspectives, 2001, 27(3):137-143.

23. Arnold F, Measuring the effect of sex preference on fertility: the case of Korea, Demography, 1995, 22(2):280-288.

24. Chowdhury MK and Bairagi R, Son preference and fertility in Bangladesh, Population and Development Review, 1990, 16(4):749-757. 
25. Huq NM and Cleland J, Bangladesh Fertility Survey, Main Report, Dhaka, Bangladesh: NIPORT, 1990.

26. Gwatkin DR et al., Socio-economic differences in health, nutrition and population, Bangladesh, Washington, DC: HNP/Poverty Thematic Group, World Bank, 2000.

27. Bairagi $\mathrm{R}$ and Rahman $\mathrm{M}$, Contraceptive failure in Matlab, Bangladesh, International Family Planning Perspectives, 1996, 22(1):2125.

28. Bairagi R, Islam MM and Barua MK, Contraceptive failure: levels, trends and determinants in Matlab, Bangladesh, Journal of Biosocial Science, 2000, 32(1):107-123.

29. Bongaarts J and Potter RG, Fertility, Biology and Behavior, New York: Academic Press, 1983.

30. Henshaw SK, Singh S and Haas T, The incidence of abortion worldwide, International Family Planning Perspectives, 1996, 25(Suppl.):30-38.

31. Islam MA, Islam MM and Chakraborty N, Plateauing of Fertility Level in Bangladesh: Exploring the Reality, Dhaka, Bangladesh: Centre for Policy Dialogue, 2001.

32. Bairagi R, Sutradhar SR and Alam A, Levels, trends and determinants of child mortality in Matlab, Bangladesh, 1966-94, Asia-Pacific Population Journal, 1999, 14(2):1-18.

33. Rodgers GB, Income and inequalities as determinants of mortality: an international cross-sectional analysis, International Journal of Epidemiology, 2002, 31(3):533-538.

34. Bongaarts J, The end of the fertility transition in the developing world, Policy Research Division Working Papers, New York: Population Council, 2002, No. 161.

\section{RESUMEN}

Contexto: Aunque la prevalencia del uso de anticonceptivos aumentó en nueve puntos porcentuales desde 1993 hasta el 2000 en Bangladesh, casi no disminuyó la tasa global de fecundidad. Métodos: Se analizaron los datos recopilados por la Encuesta Demográfica y de Salud de Bangladesh en 1999-2000 y por el Sistema de Vigilancia Demográfica Matlab entre 1978 y 2001, para explicar la falta de cambio de la tasa de fecundidad y examinar la relación entre la prevalencia del uso de anticonceptivos, la razón de abortos, la fecundidad deseada y la fecundidad observada.

Resultados: Después que se inició el programa de planificación familiar de salud materno-infantil, en parte de Matlab, en 1977, la tasa global de fecundidad en el área del programa disminuyó de 4.8 hijos por mujer en 1979 a 2.9 en 2000, en tanto que en el área de comparación, la fecundidad disminuyó de 6.3 a 3.5. Durante este período aumentó la prevalencia de anticonceptivos, del 30\% al 70\% y del 16\% al 50\% en las dos áreas, respectivamente; al mismo tiempo, la razón de abortos disminuyó de 4.3 a 3.6 en el área del programa, pero aumentó de aproximadamente 2.0 a 8.2 en el área de comparación. En ambas áreas las tendencias fueron similares con respecto a la fecundidad deseada, la cual disminuyó de aproximadamente 4.0 hijos por mujer en 1979 a 2.5 hijos en el año 2000. Entre las mujeres en cada nivel de paridad, la fecundidad generalmente disminuyó a medida que aumentó el número de hijos va- rones, y la fecundidad más elevada fue entre las que no tenían varones.

Conclusiones: La preferencia por los hijos varones y la preocupación de los padres por la mortalidad en la infancia y en la niñez puede explicar, en parte, la diferencia entre la fecundidad deseada y la fecundidad observada. La reducción de la lactancia materna y el aumento del uso de los métodos anticonceptivos menos efectivos pueden ser la causa de la incongruencia en la relación entre el uso de anticonceptivos y la fecundidad.

\section{RÉSUMÉ}

Contexte: La prévalence contraceptive a augmenté de neuf points de pourcentage entre 1993 et 2000 au Bangladesh. Le déclin de l'indice synthétique de fécondité demeure pourtant pratiquement nul.

Méthodes: Les données de l'Enquête démographique et de santé bangladaise de 1999-2000 et celles de la zone du Système de surveillance démographique de Matlab recueillies entre 1978 et 2001 ont été analysées en vue d'expliquer la fécondité inchangée et d'examiner les rapports entre la prévalence contraceptive, le rapport d'avortement, la fécondité désirée et l'indice synthétique de fécondité.

Résultats: Après l'introduction d'un programme de santé maternelle et infantile et de planification familiale dans une partie de Matlab en 1977, l'indice synthétique de fécondité est passé, dans la zone d'intervention, de 4,8 en 1979 à 2,9 en 2000, tandis que la fécondité se réduisait, dans la zone de comparaison, de 6,3 à 3,5. Durant cette période, la prévalence contraceptive est passée de 30\% à $70 \%$ et de $16 \%$ à $50 \%$, respectivement, dans les deux zones, tandis que le rapport d'avortement se réduisait de 4,3 à 3,6 dans la zone d'intervention mais grimpait, d'environ 2.0, à 8,2 dans la zone de comparaison. Les tendances de fécondité désirée paraissent similaires dans les deux zones, déclinant d'environ 4,0 enfants par femme en 1979 à environ 2,5 en 2000. À chaque rang de parité, la fécondité se réduit généralement à mesure que le nombre de fils augmente; elle atteint son plus haut niveau parmi les femmes sans fils.

Conclusions: La préférence pour les enfants de sexe masculin et les inquiétudes parentales de mortalité infantile et postinfantile peuvent expliquer, en partie, la différence entre le nombre d'enfants désiré et la fécondité. La réduction de l'allaitement maternel, unie à l'accroissement de méthodes contraceptives moins efficaces, pourrait être responsable du rapport contradictoire entre pratique contraceptive et fécondité.

\section{Acknowledgments}

The authors thank Chanda Akeda of Fordham University for editing an earlier version of the manuscript and UNFPA, Dhaka, for funding the project.

Author contact: unnati@bdmail.net 